http://jmscr.igmpublication.org/home/

ISSN (e)-2347-176x ISSN (p) 2455-0450

crossref DOI: https://dx.doi.org/10.18535/jmscr/v7i12.89

\title{
Simplifying the MHC Act, 2017
}

\author{
Authors \\ Dr U. Sardesai ${ }^{1}$, Dr S.P Baral ${ }^{2}$ \\ ${ }^{1}$ M.D \& Associate Professor, Department of Psychiatry, MGM Medical College, Indore \\ ${ }^{2}$ D.P.M \& M.D,, Department of Psychiatry, MGM Medical College, Indore \\ *Corresponding Author \\ Dr Swayam Prava Baral \\ D.P.M \& M.D, Department of Psychiatry, MGM Medical College, Indore, MP, India
}

\section{Introduction}

Every ACT is a long complicated document taking a long time for a busy clinician to interpret and apply in the daily OPD and ward management. Keeping in mind the heavy patient load and shortage of time for doctors, here is an attempt to simplify the admission and discharge processes in the act in the form of easy to access flow charts. 
Chapter XII

Admission, Treatment and Discharge

$$
\text { INDEPENDENT }
$$

MINOR

SUPPORTED

\section{SECTION 86,88}

\section{INDEPENDENT(Admission ,treatment and discharge)}
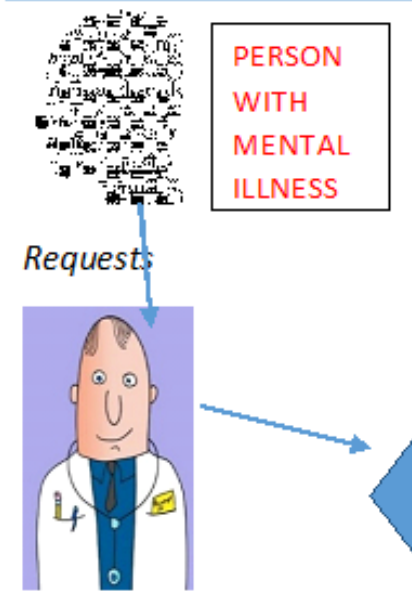

M edical officer ( $\mathrm{MO}$ ) or mental health Professional (M HP) in charge of the M ental Health establishment (M HE)
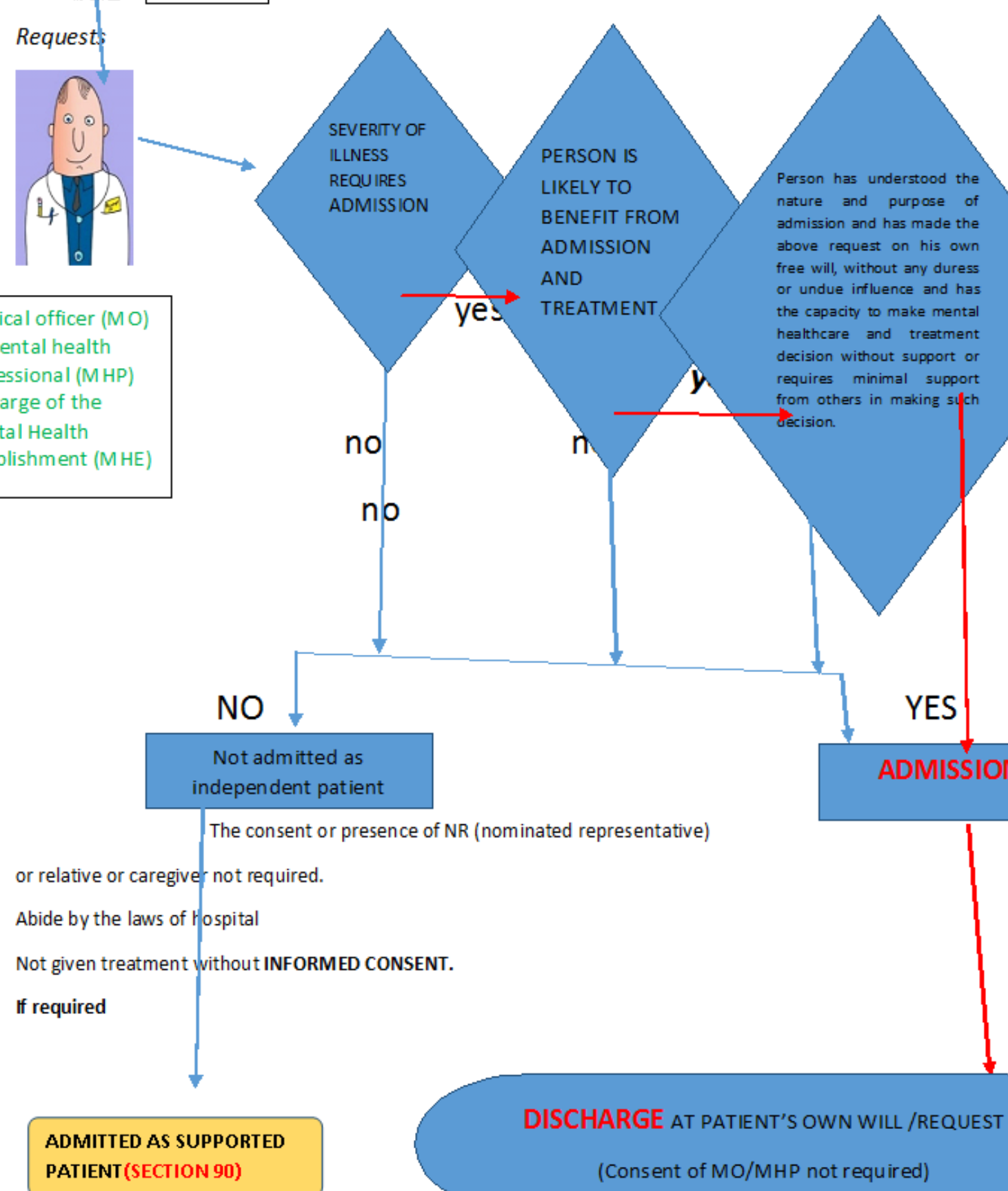
AND TREATMENT free will, without any duress or undue influence and has the capacity to make mental healthcare and treatment decision without support or requires minimal support from others in making sulch

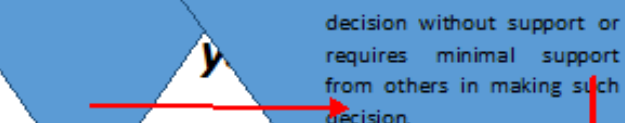
PATIENT(SECTION 90) 


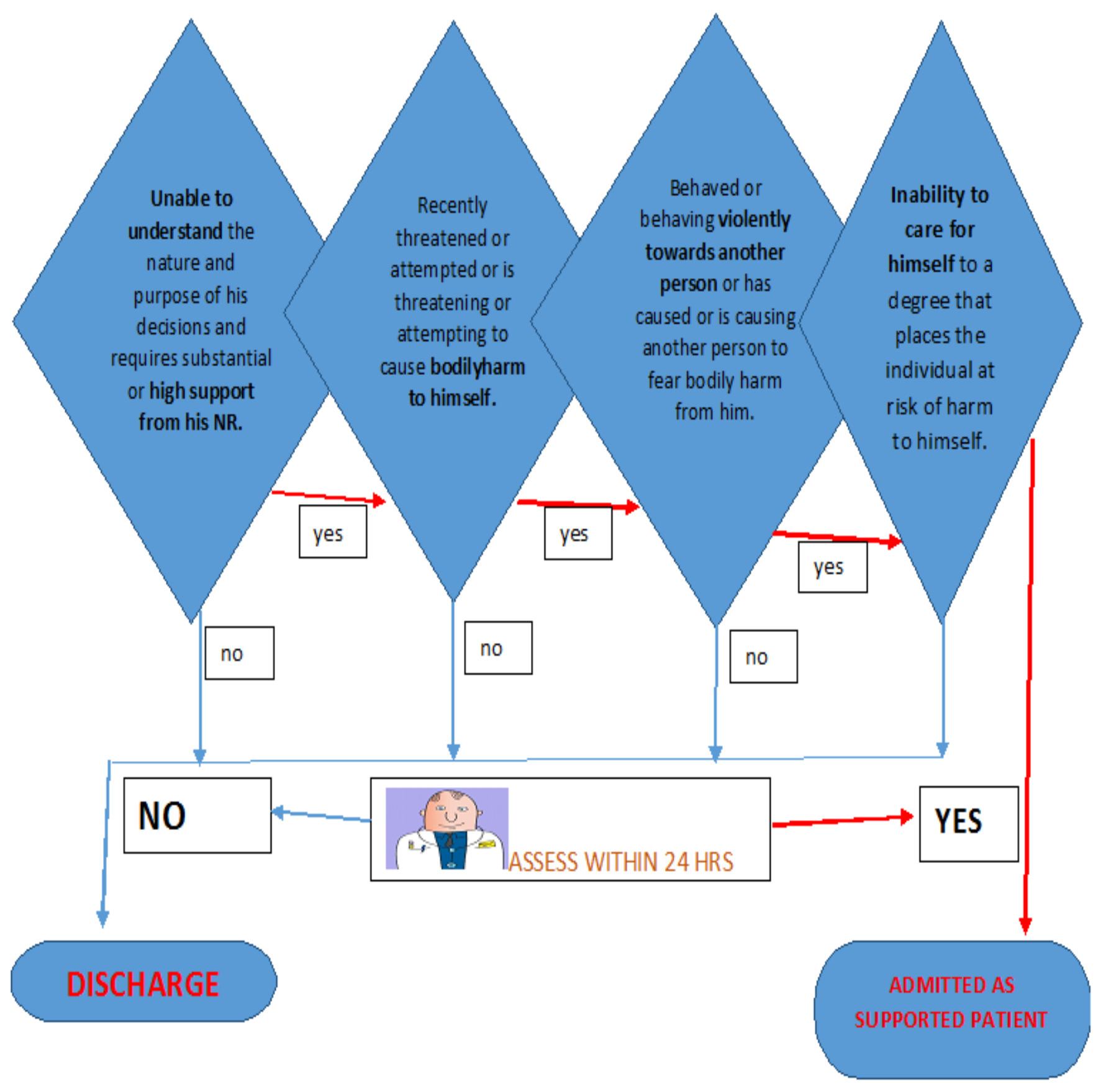


MINOR (Admission, treatment and discharge)

\section{SECTION 87}

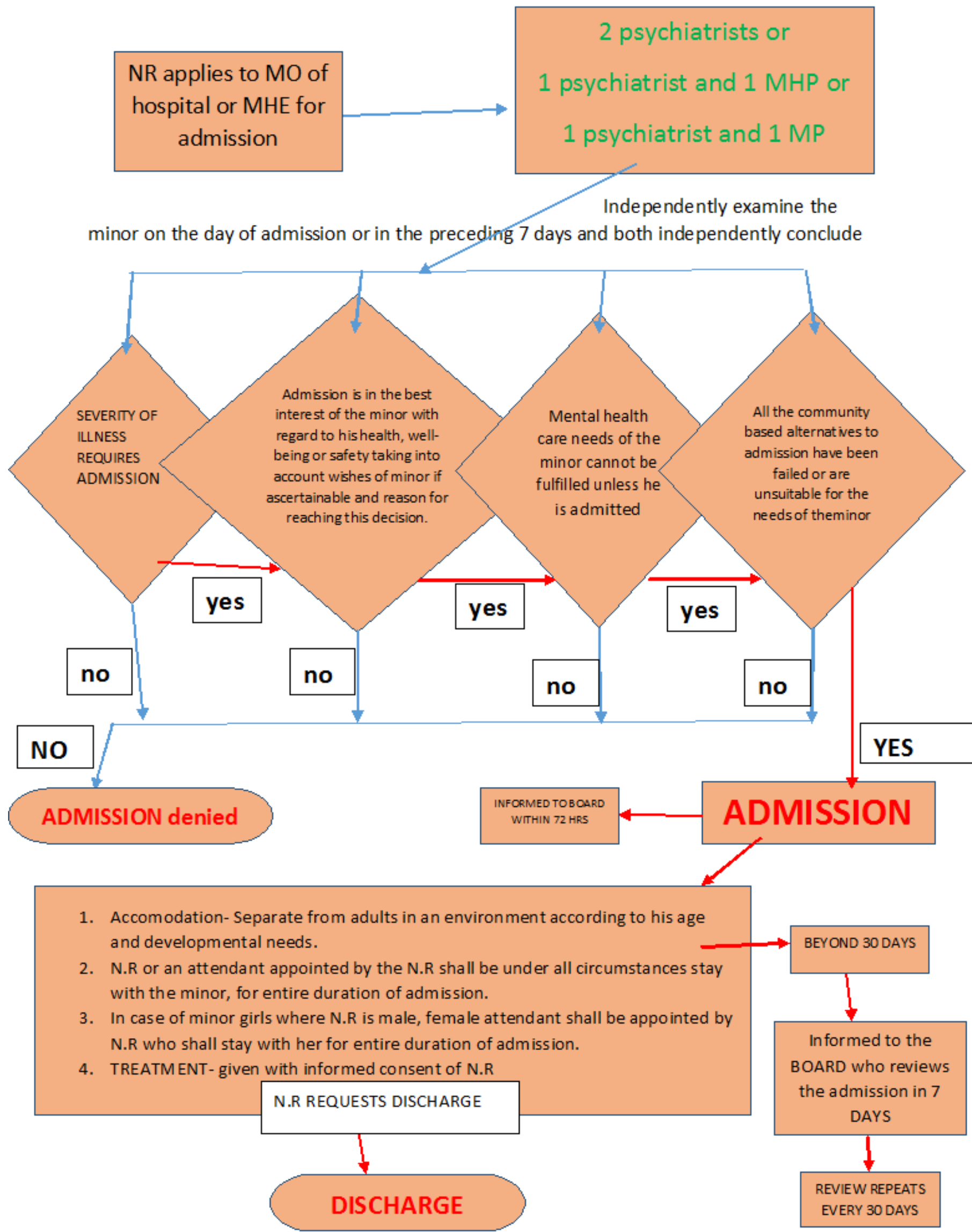




\section{SUPPORTED(Admission, treatment and discharge)}

\section{SECTION 89\{ADMISSION UPTO 30 DAYS\}}

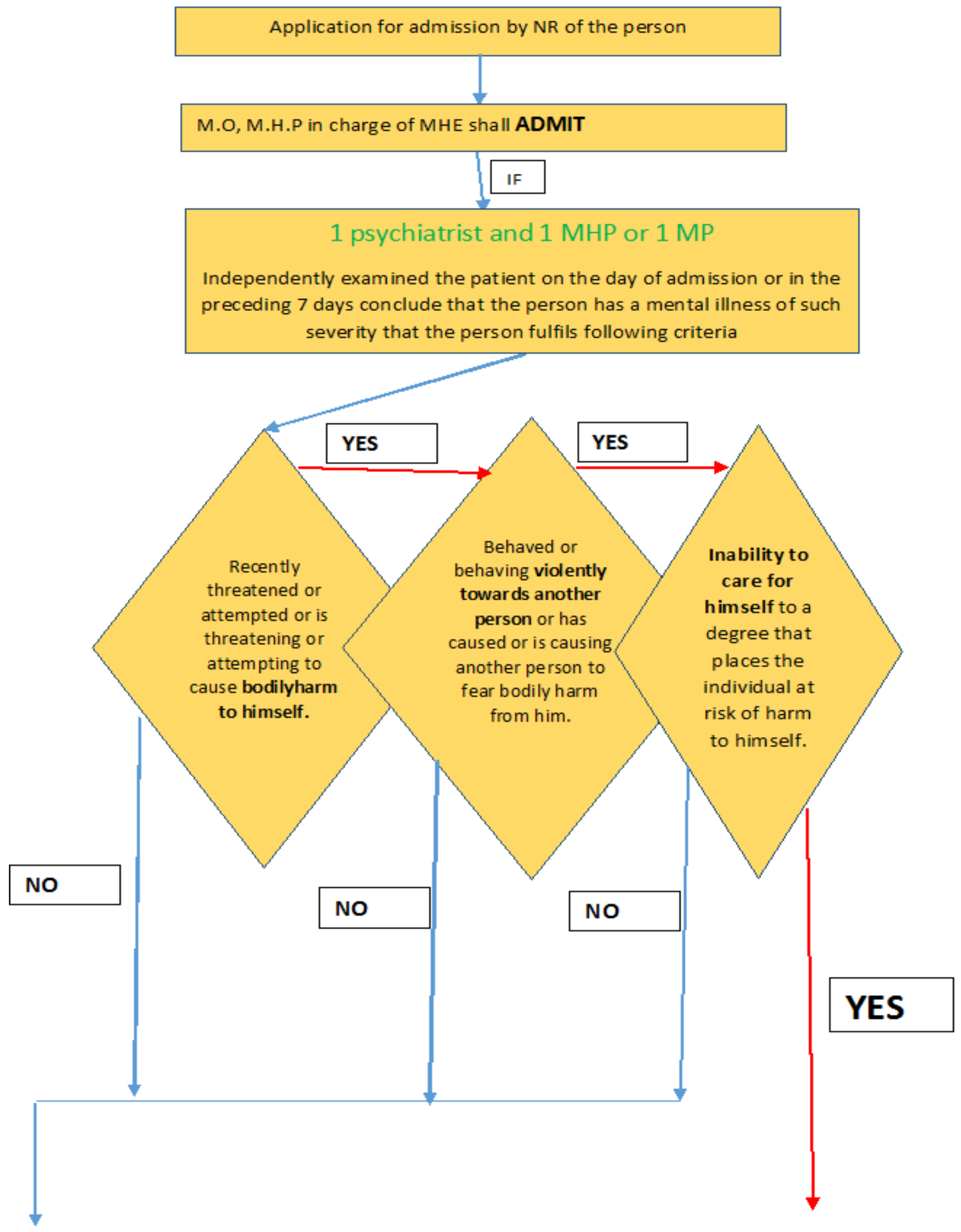




\section{JMSCR VoI||07||Issue||12||Page 486-495||December}

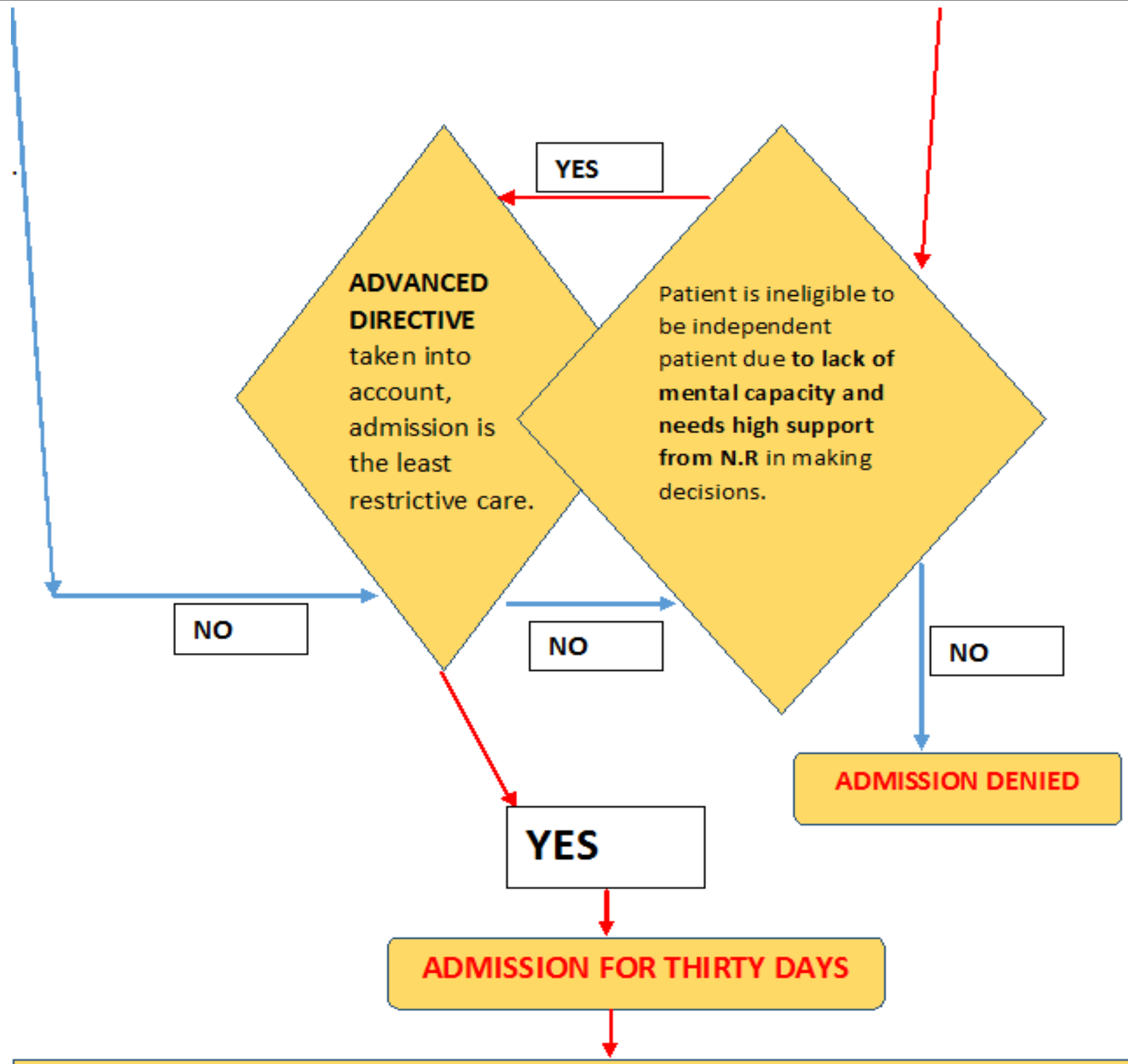

TREATMENT according to

-ADVANCED DIRECTIVE IF ANY

-INFORMED CONSENT OF THE PATIENT WITH SUPPORT OF N.R (Consent to be recorded in medical records and capacity of the patient to give consent to be reviewed every 7 days by M.O or M.H.P incharge of MHE.

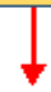

BOARD has to be reported -within 3 days of admissions of a woman $/ \mathrm{minor}$

-within 7 days of admissions of any person not being a woman or minor

Person /N.R/ a representative of a registered NGO with the consent of the person, may apply to the BOARD for review of the admission decision of the M.O /MHP in charge of MHE. [BOARD SHALL REVIEW THE DECISION IN 7 DAYS]

\section{END OF 30 DAYS}




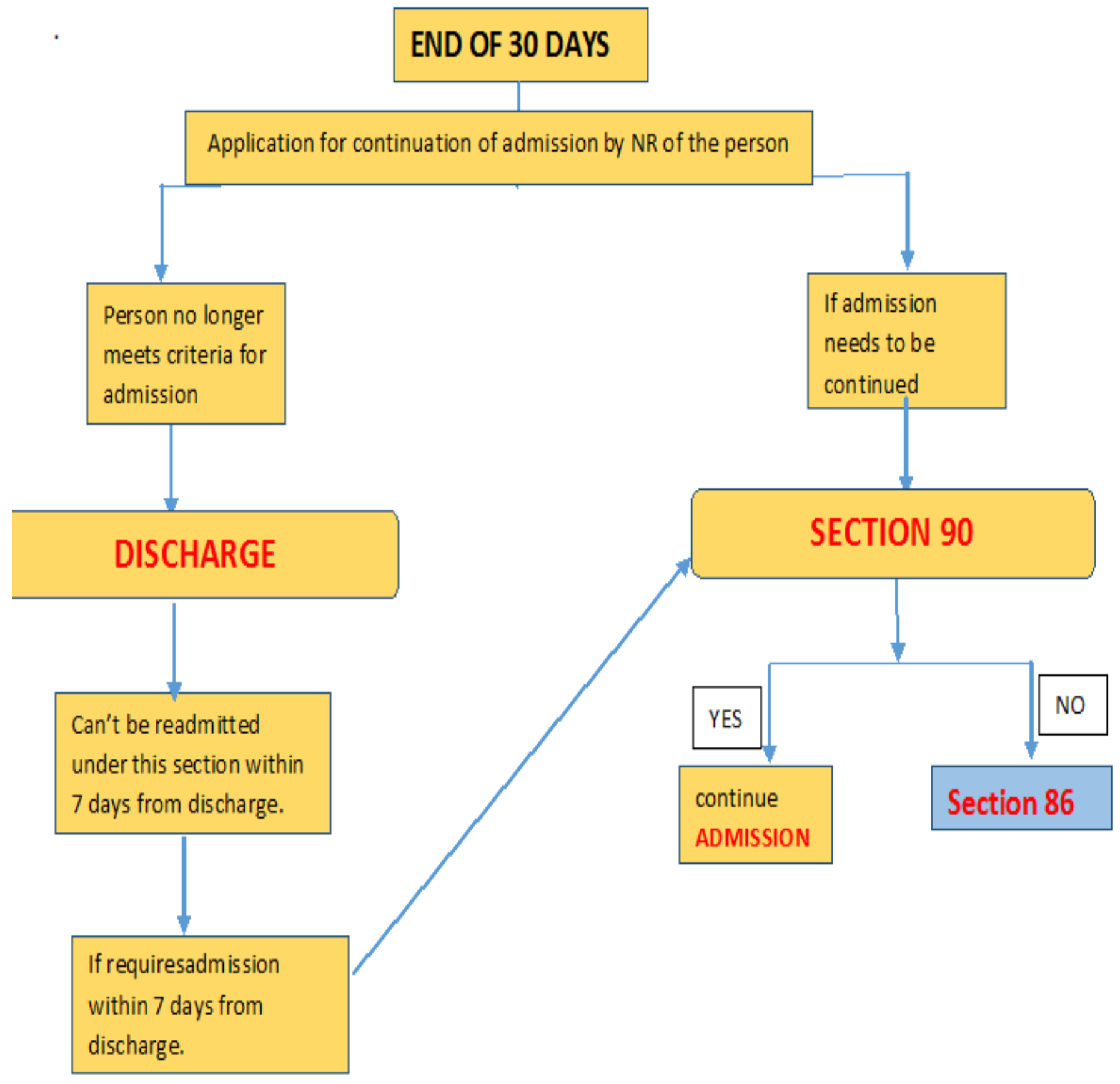




\section{SUPPORTED(Admission, treatment and discharge)}

\section{SECTION 90 \{ADMISSION beyond 30 DAYS \}}

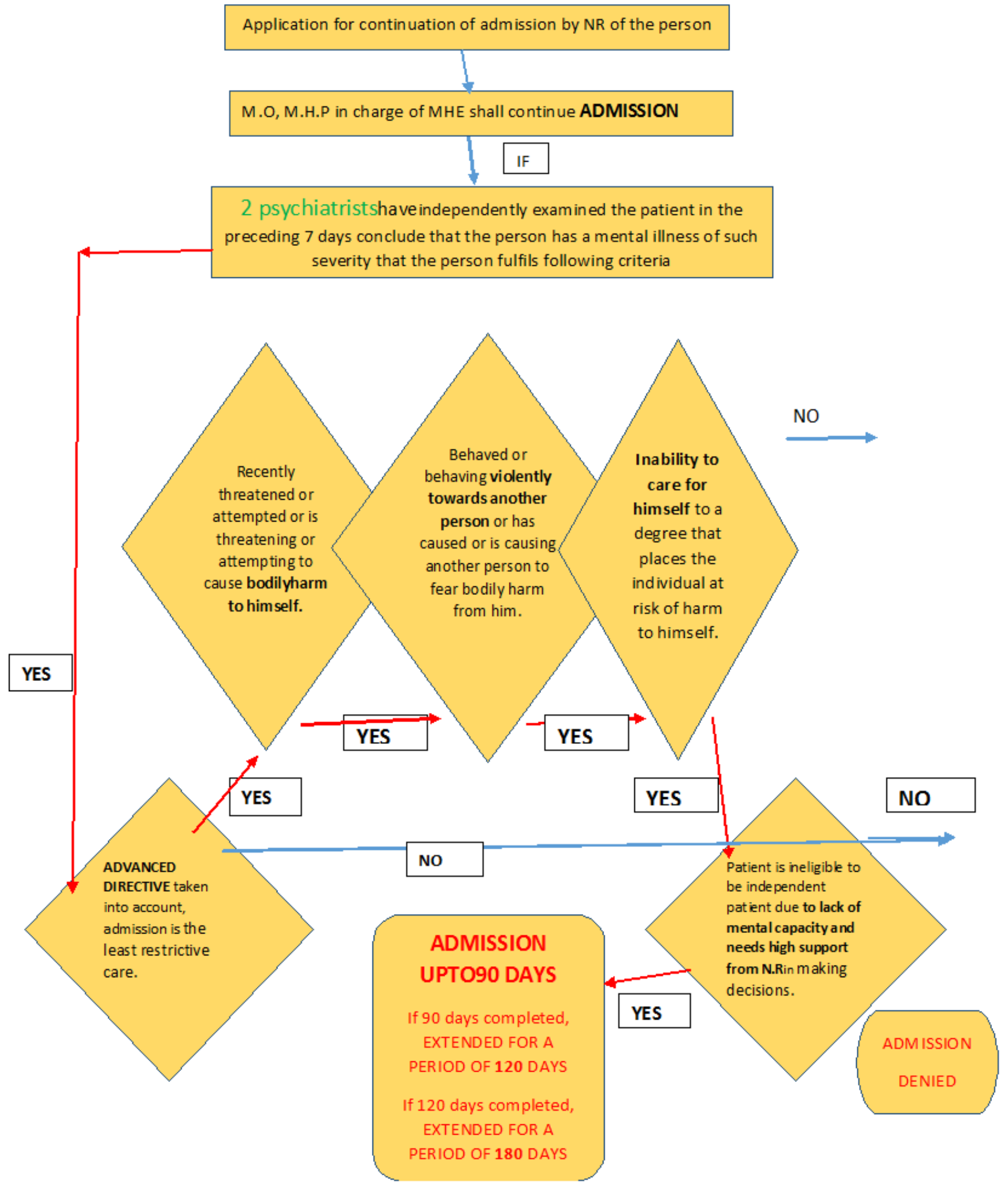




\section{TREATMENT according to}

-ADVANCED DIRECTIVE IF ANY

-INFORMED CONSENT OF THE PATIENT WITH SUPPORT OF N.R (Consent to be recorded in medical records and capacity of the patient to give consent to be reviewed every 15 days by M.O or M.H.P incharge of MHE.

BOARD has to be reported by M.O/M.H.P within 7 days of admissions or readmissions.

BOARD shall permit such admissions or read missions or order discharge within $\mathbf{2 1}$ days from the date of last admissions or readmissions.

While doing the above it shall exam ine the need of institutional care to such person and whether such care can't be provided in less restrictive settings based in the community.

M.O/Psychiatrist in charge of treatment has to submit a plan for community based treatment and progress made or likely to be made towards realising the plan.

M.O/M.H.P is of the opinion that

Patient no

longer meets the

criteria for

admission.

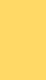

Person /N.R/ a

representative of a registered NGO with the consent of the person, may apply to the BOARD for review of the decision of the M.O /MHP in charge of MHE regarding admission or discharge.
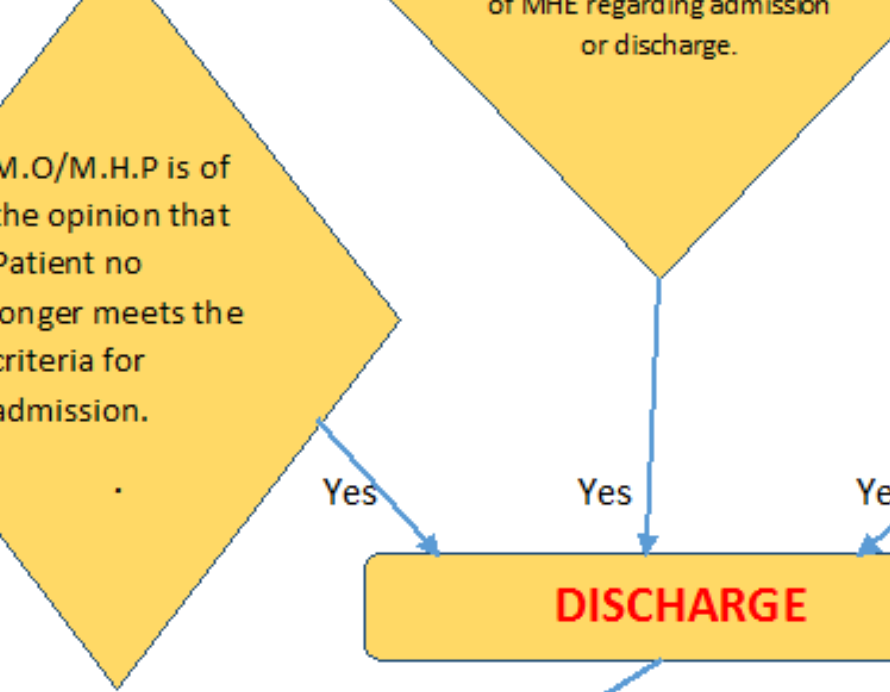

Yes
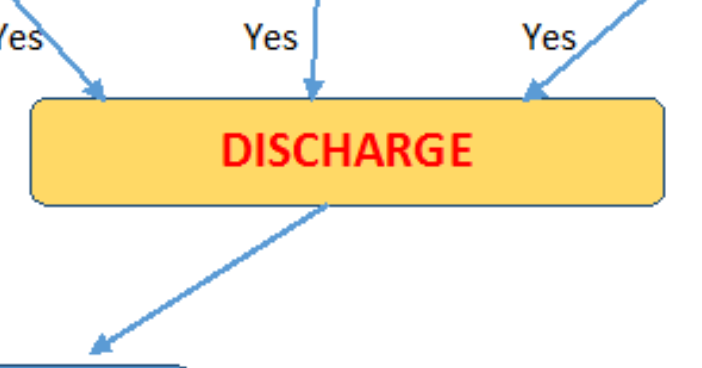

SECTION 86 (Can continue as

independent patient)
BOARD can refuse to permit such admissions or extension, after expiry of stipulated periods if Patient no longer meets the criteria for admission. 


\author{
Abbreviations \\ N.R - Nominated Representative \\ M.O - Medical Officer \\ M.P- Medical Practitioner \\ M.H.P- Mental Health Professional \\ M.H.E- Mental Health Eshtablishment
}

\title{
Reference
}

1. Gazette of India For Mental Health Act 2017. 